\section{$\underset{\substack{\text { hommes } \\ \text { \& migrations }}}{ }$}

\section{Hommes \& migrations}

Revue française de référence sur les dynamiques

migratoires

1286-1287 | 2010

Les migrations subsahariennes

\title{
Entretien avec Xuly Bët
}

\section{Xuly Bët}

\section{(2) OpenEdition \\ Journals}

Édition électronique

URL : http://journals.openedition.org/hommesmigrations/1741

DOI : 10.4000/hommesmigrations. 1741

ISSN : 2262-3353

\section{Éditeur}

Musée national de l'histoire de l'immigration

\section{Édition imprimée}

Date de publication : 1 juillet 2010

Pagination : 160-161

ISSN : 1142-852X

Référence électronique

Xuly Bët, «Entretien avec Xuly Bët », Hommes \& migrations [En ligne], 1286-1287 | 2010, mis en ligne le 29 mai 2013, consulté le 03 mai 2019. URL : http://journals.openedition.org/hommesmigrations/1741 ; DOI : 10.4000/hommesmigrations. 1741 


\section{Entretien avec Xuly Bët}

Réalisé dans le cadre de l'émission de Aligre FM en partenariat avec la revue Hommes et Migrations, intitulée Composition française, diffusée le 6 septembre 2010

"En wolof 'Xuly Bët' signifie regarder le monde au-delà des apparences. J'ai grandi au Mali, mais en raison de la situation politique tendue, je me suis baladé dans le monde avec mes parents qui avaient des opinions politiques assez controversées. J'ai quitté le Mali quand mon père a dû partir, après sept ans de détention dans des conditions assez déplorables. Ce départ a laissé des stigmates et une nostalgie du pays de mon enfance dont j’avais été arraché.

\section{L'enfance de l'art}

J'ai un esprit ouvert à l'art. Au départ, j'ai fait des études d'architecture. Quand j'étais à Dakar, je suivais le travail de beaucoup d'artistes sénégalais comme Joha Kam qui m'ont aussi aidé. La mode est venue à moi de façon naturelle. L'étoffe est un matériau beaucoup plus léger que le béton, dont la force de représentation puissante est liée au monde politique et aux apparatchiks. Elle correspond davantage à mon état d'esprit. Quand j'étais gosse, au milieu des années soixante-dix, on allait souvent chez le tailleur avec des idées précises : des pantalons pattes d'éléphants, des Platform Shoes appelées 'têtes de nègre'. Malgré l'effet de mode, il y avait déjà de la création : on fouinait les tissus et nos vêtements avaient des petites touches personnelles.

Les grands frères de la mode sont venus avant moi. Je suis de la génération des années soixante, née au lendemain des indépendances des pays africains. On avait un idéal politique. Cette victoire a été fauchée par certains leaders qui ont mené l'Afrique au gouffre. Les jeunes créateurs africains ont une démarche aiguë, moderne et très ouverte. Ils se posent des questions sur l'avenir de l'Afrique, notamment pour produire leurs modèles.

\section{Une mode sans étiquettes}

On me prête différentes étiquettes : grunge, funk, ethnic, rock. La problématique de la 'mode ethnique' que soulèvent les jeunes créateurs africains montre que l'Afrique veut sortir de l'ornière dans laquelle on l'a fourrée. L'Afrique a été pillée, mais elle a aussi influencé le monde. Elle ne correspond pas aux images d'Epinal qu'on lui 
attribue. Les indépendances ont cimenté des nations et fixé des enjeux pour les populations. Les créateurs s'interrogent sur la façon d'exprimer les aspirations actuelles des Africains et du monde: l'Afrique va-t-elle se cantonner dans ses habitudes ou avancer? Va-t-on continuer à la fouler aux pieds ou traiter les aspirations, le besoin de progrès des populations? La diversité de l'Afrique en fait toute sa richesse. C'est un continent en pleine ébullition. Aujourd'hui la notion de 'mode ethnique' reste dans la facilité sans poser les vraies questions.

La connaissance est dans la différence. Appréhender l'autre, tout en restant campé dans sa propre identité, ne rime à rien. Beaucoup de créateurs en France ont marqué le textile de leur empreinte. Ce sont des pionniers. Je ne renie pas leur influence sur mon travail. La culture est une donnée universelle à partir du moment où elle est publiée. Je suis malien, mais j’ai beaucoup appris des créateurs français comme Yves Saint Laurent, Alaïa, Paco Rabanne, Castelbajac, Gaultier qui ont un talent immense : on ne peut pas passer à côté d'eux. C'est une équation personnelle qui nous encourage à se demander qu'elle est notre propre mode. Souvent, dans les discours officiels sur la mode en France ou en Afrique, la tendance est plutôt au conservatisme, au repli sur soi et, de fait, ma création apparaît comme une culture à contre sens. J'ai d'ailleurs ouvert un lieu, au 95 boulevard Beaumarchais, destiné aux autres créateurs et aux expositions régulières d'artistes, comme à la Factory.

\section{Créer pour tous les corps}

Un créateur de mode découvre les vêtements à travers les gens qui les portent. En tant qu'Africain, je suis très sensible aux rondeurs, à la sensualité des corps, la féminité à fleur de peau. Ce trait commun caractérise la mode des créateurs africains qui prennent en compte la diversité des corps. Il est nécessaire d'ouvrir, à travers mes créations, un espace de vie en regardant les vêtements portés. On apprend beaucoup à travers les clients. Généralement, je cherche à désenclaver la mode au profit d'une approche plus démocratique. Même si elle est glamour, ma mode se veut accessible. L'adhésion se fait surtout autour du portefeuille.

La mode peut être un vecteur économique et social puissant. Je travaille avec des artisans et des teinturières au Mali et je leur apporte une approche différente sur le traitement des matériaux. Avec Leclerc, je travaille sur la filière du coton bio pour développer la distribution dans les centres Leclerc et contrer la situation dramatique dans laquelle ils se trouvent actuellement. L'éthique correspond à mon état d'esprit et tant mieux!" 